\title{
Aproximación a las barreras jurídicas y procedimentales en la restitución de tierras. Estudio de caso: mujeres de Ataco, sur del Tolima ${ }^{1}$ Approach Legal and Procedural Barriers to Land Restitution. Case Study: Mujeres de Ataco, Southern Tolima
}

\author{
Katherine Tabares Acevedo \\ Universidad del Valle, Cali, Colombia. \\ tabares.katherine@correounivalle.edu.co | https://orcid.org/0000-0003-0677-1298
}

Recibido: 31 de agosto 2020. Aprobado: Septiembre 22 del 2020.

DOI: $10.25100 /$ lamanzanadeladiscordia.v15i2.10872

Artículo de investigación

¿Cómo citar este artículo? / How to quote this article? Tabares Acevedo, Katherine. (2020). Aproximación a las barreras jurídicas y procedimentales en la restitución de tierras. Estudio de caso: mujeres de Ataco, sur del Tolima. La Manzana de la Discordia, 15(2), 1-29. doi:10.25100/lamanzanadeladiscordia.v15i2.10872

\footnotetext{
${ }^{1}$ Artículo producto de la investigación doctoral en curso, titulada: Procesos de restitución en mujeres campesinas. Caso: Córdoba y Tolima.
} 
Aproximación a las barreras jurídicas y procedimentales en la restitución de tierras. Estudio de caso: mujeres de Ataco, sur del Tolima

\section{Resumen}

La ley de víctimas y restitución de tierras, 1448 de 2011, indica en general los procedimientos de actuación del Estado en los procesos de despojo y abandono de tierras a causa del conflicto armado. En este contexto, el presente artículo expone algunas de las barreras jurídicas y procedimentales que viven las mujeres restituidas de la micro zona de Ataco, sur del departamento de Tolima, Colombia. Para ello se realizó una revisión documental sobre sentencias de la oficina territorial y algunos informes institucionales que dan cuenta del avance y cumplimento. También se realizaron entrevistas semi-estructuradas a mujeres participantes del proceso.

Las decisiones que se han tomado respecto a la restitución de tierras expresan diferencias significativas entre hombres y mujeres. En especial, por la informalidad en la tenencia de la tierra y el desconocimiento de los procedimientos jurídicos en cuanto la restitución de tierras. Dichas situaciones hacen que las mujeres expresen que, si bien observan una respuesta estatal, tienen temores en cuanto: acciones de violencia que las lleven a tener que desplazarse nuevamente; precariedad de las viviendas recibidas; la falta de acceso a servicios públicos; diferencias entre ellas y sus hijos e hijas en relación a su vínculo con la tierra.

Palabras claves: Mujeres restituidas, Abandono, Sentencias, Conflicto armado.

\section{Summary}

The Victims and Land Restitution Law, 1448 of 2011, generally indicates how the State acted in front of the process of dispossession and abandonment of land due to the armed conflict. This article exposes the legal and procedural barriers experienced by returned women in the Ataco microzone, southern of Tolima. For that purpose, a documentary review was carried out on judgments of the territory for those cases and some institutional reports that show the progress and compliance with the judgments. Also, semi-structured interviews were conducted with women participating in the process.

Decisions that have been made regarding land restitution, express significant differences between men and women. Especially, the informality in land ownership, and the unawareness of the legal procedures aboud regarding land restitution. These situations make women express that although they observe a state response, they have fears regarding: violence's acts that lead them 
displacement again; precariousness of the houses received; lack of access to public services; the distance between them and their sons and daughters in relation to their bond to the land.

Key works: Returned Women, Abandonment, Judgments, Armed Conflict.

\section{Introducción}

El presente artículo se presenta como un primer avance de la investigación doctoral en desarrollo, es por esto que esboza algunos elementos que la implementación de la política de restitución de tierras devela cuando los sujetos restituidos son mujeres y en casos de abandono de una región particular. El texto presenta cuatro apartes. Para la comprensión del tema que trata el artículo, primero se hace un planteamiento sobre el problema de la propiedad rural en la población femenina. Después se presenta la categoría de género en la política de restitución de tierras, aclarando lo que se ha discutido hasta el momento como limitaciones en la implementación de la política, así como el concepto que se usa en la investigación en general. A modo de contexto, se presenta la zona objeto de abandono por parte de las mujeres y algunas características de los actores armados que hicieron presencia en el territorio. Finalmente, se describe en qué consiste el proceso de restitución y cómo en la micro zona de Ataco, a partir de las primeras sentencias emitidas en el año 2013, se pueden observar algunas barreras jurídicas en las mujeres restituidas.

\section{Sobre el problema de la propiedad rural en general}

En Colombia y en Latinoamérica se han adelantado diferentes estudios sobre las mujeres rurales/campesinas desde diferentes perspectivas. Entre los temas tratados se encontraron: el acceso y la propiedad de la tierras (Carmen Diana Deere, 2000; Magdalena León, 1986; y Donny Meertens, 2006, 2016, 2017 durante las décadas de 1980, 1990 y 2000); la organización y movilización de las mujeres rurales (Giarracca, 2001 y Norma Villarreal, 2004); la contribución de las mujeres a la agricultura y la seguridad alimentaria (Cepal, 2011); los análisis multidimensionales sobre la situación de las mujeres rurales (Fao, 2009 y Oxfam, 2016); y finalmente, de manera reciente la manera como las reformas en ley de tierras acentúan la inequidad de la tenencia y la favorabilidad a los proyectos agroindustriales (Meertens, 2017). 
En todos los estudios mencionados se da cuenta de las dificultades que viven las mujeres en materia productiva y de la propiedad de la tierra. Sosteniendo la discusión sobre el aporte económico de las mujeres en cuanto la reproducción social y las necesidades de apoyo para aumentar su producción; aspectos que pueden mejorar la calidad de vida de los hogares familiares cuya jefatura femenina cada vez es más alta.

Por su parte, el PNUD en el Informe de Desarrollo Humano del 2011, señalaba que el sector campesino en Colombia "está constituido por alrededor de siete millones de personas, y produce algo más de la mitad de los alimentos que se consumen en Colombia" (PNUD, 2011, p. 65). Sin embargo, el sector campesino enfrenta diversas dificultades en cuanto:

(a) el acceso a la tierra, que le impide obtener un ingreso digno; (b) el acceso al crédito, que afecta sus posibilidades de salir de la pobreza; (c) la escasa asistencia técnica, que limita su acceso al conocimiento y la obtención de mejores resultados productivos; (d) las amenazas contra su vida y sus derechos, que ponen en riesgo el núcleo esencial del disfrute de una vida larga y saludable; y, (e) la deficiencia de su participación política y la fragmentación de su acción colectiva, lo que impide que su voz y reivindicaciones sean atendidas por el sistema político. (p. 65)

La característica común sobre lo descrito hasta el momento refiere que las mujeres en el sector rural tienen menores oportunidades en materia del mercado laboral, son las peor remuneradas y tienen menor acceso a la tierra. Aspectos que deben resaltarse porque demuestra claramente una situación de desventaja de las mujeres campesinas/rurales en un orden estructural y cultural general.

Dificultades que no son otra cosa que problemas históricos del Estado colombiano y que no ha logrado solventar a pesar de sus esfuerzos tímidos en materia de reformas agrarias (Ley 30 de 1988 y Ley 160 de 1994) y propuestas puntuales de desarrollo rural. Pertinente de anunciar ya que afecta y se vive de modo particular de acuerdo con el género.

Al observar los datos disponibles para analizar el tipo de vínculo que se tiene con la tierra entre hombres y mujeres víctimas del conflicto armado, la tercera encuesta de verificación de los derechos de la población desplazada (2010), registró que los hombres son quienes en su mayoría 
son propietarios, son los que además, heredan la propiedad y en un número reducido tienen una titularidad compartida entre hombres y mujeres.

Tabla 1. Tenencia de tierra y género.

\begin{tabular}{|c|c|c|c|}
\hline $\begin{array}{c}\text { Forma de tenencia } \\
\text { de la tierra forzada a } \\
\text { abandonar o } \\
\text { despojada }\end{array}$ & Hombre (\%) & Mujer (\%) & $\begin{array}{c}\text { Hombre y Mujer } \\
\qquad(\%)\end{array}$ \\
\hline Propietario(a) & 64,2 & 25,5 & 9,3 \\
\hline Poseedor (a) & 58,9 & 26,7 & 14,5 \\
\hline Ocupante de baldío & 70,0 & 8,9 & 21,1 \\
\hline Ocupante de hecho & 55,4 & 25,0 & 19,6 \\
\hline Heredero & 56,3 & 32,5 & 11,2 \\
\hline
\end{tabular}

Fuente: Encuesta Nacional de Verificación de los Derechos de la Población Desplazada, octubre de 2010.

Los datos que registra la tabla ilustran un lugar de desventaja de las mujeres respecto a los hombres en materia de propiedad. Según los datos de la encuesta de verificación mencionada:

"Estima en 6.556.978 las hectáreas abandonadas y despojadas en 270.680 predios. El despojo se centró en el microfundio y la pequeña propiedad hasta 20 hectáreas (el 73\% de los predios), y en las medianas entre 20 y 500 hectáreas (26,6\% de los predios). Es evidente que las principales víctimas fueron los campesinos. Además, los departamentos de mayor despojo han sido en su orden Antioquia, Putumayo, Caquetá, Bolívar, Nariño, Meta, Tolima, Cauca, Córdoba, Cesar, Sucre y Chocó, los que cubren el 74,4\% del área abandonada y el 77,9\% de los predios” (PNUD, 2011, p. 71).

En consonancia con el informe del PNUD (2011), se describió que las mujeres pasan por una triple discriminación: "por vivir en el campo, por ser mujeres y por ser víctimas de la violencia". La primera explicada en oposición a lo que ofrece el mundo urbano respecto al rural (agudización de la desigualdad social), la segunda relacionada con la polaridad construida y valorada entre aquello que hombres y mujeres puede hacer en el campo desde los oficios y sector 
productivo. Ahora, sumarle la situaciónn de víctima del conflicto armado es indicar otra característica a la deuda histórica en materia de respuesta del Estado a las víctimas, en particular, cuando le ha costado reconocer que la proporcionalidad del conflicto armado es diferenciada en relación al género.

Así las cosas, el campesinado en general, mantiene problemas históricos en cuanto a formalización de la tierra, productividad y desarrollo rural. Situación que se agudiza en las mujeres campesinas/rurales. De acuerdo con el informe sobre: “Tierra, derechos y género. Leyes, políticas y prácticas en contextos de guerra y paz”, Meertens (2006) reconoce que, si bien en términos materiales persisten las brechas de género en cuanto a la propiedad, en lo legislativo se encuentran algunos avances en: la Ley de Mujer Cabeza de Hogar (No. 82 de 1993), las dos Leyes de Mujer Rural (1984 y 2003) y algunos artículos de la Ley 160 de Reforma Agraria (1994). La autora refiere que si bien desde la Ley 135 de 1961 se reconoció que los arrendatarios, aparceros o trabajadores sin tierra, requerían de un proceso de formalización y apoyo, solo se priorizó al jefe de hogar y no se consideraba como tal a las mujeres. Teniéndose que esperar hasta el año 1984 para reconocerse a la mujer como productora agrícola y configurarse la primera política nacional para la mujer campesina.

Es este contexto cuando debe señalarse que el conflicto armado agudizó la problemática de las mujeres en el campo. Así después de una serie de acciones de movilización legal por parte de diferentes organizaciones de mujeres desplazadas, la Corte Constitucional se pronunció a través de la Sentencia T- $025^{2}$ y sus Autos 092 y 237 de $2008^{3}$, reconociendo el impacto y vulneración de los derechos de las mujeres, así como la obligación del Estado en garantizar con medidas

\footnotetext{
2 Corte Constitucional, Magistrado Ponente Carlos Gaviria Díaz, de marzo 29 de 2000. "En razón de esta multiplicidad de derechos constitucionales afectados por el desplazamiento, y atendiendo a las aludidas circunstancias de especial debilidad, vulnerabilidad e indefensión en la que se encuentran los desplazados, la jurisprudencia constitucional ha resaltado que éstos tienen, en términos generales, un derecho a recibir en forma urgente un trato preferente por parte del Estado. Este derecho al trato preferente constituye, en términos de la Corte, el "punto de apoyo para proteger a quienes se hallan en situación de indefensión por el desplazamiento forzado interno", y debe caracterizarse, ante todo, por la prontitud en la atención a las necesidades de estas personas, ya que "de otra manera se estaría permitiendo que la vulneración de derechos fundamentales se perpetuara, y en muchas situaciones, se agravara" (Pág. 1).

${ }^{3}$ Corte Constitucional, Auto 092 de 2008, Magistrado Ponente Manuel José Cepeda Espinosa, catorce (14) de abril de dos mil ocho (2008), Pág., 51. La Corte afirma "la precariedad de la posición de la mujer colombiana frente a la propiedad constituye un factor causal del impacto de género manifiestamente desproporcionado". Corte Constitucional, Auto 237 de 2008, Magistrado Ponente Manuel José Cepeda Espinosa, Diecinueve (19) de Septiembre de dos mil ocho (2008) - Incumplimiento de las órdenes impartidas en el Auto 092 de 2008 para proteger los derechos fundamentales de las mujeres en desarrollo de la Sentencia T- 025 de 2004.
} 
diferenciales el goce efectivo de sus derechos. Jurisprudencia que marcaron un referente de acción institucional y un marco del derecho para las mujeres víctimas del conflicto armado en su situación nada favorable en materia de tierras.

\section{Sobre la categoría de género en la Ley 1448, ley de víctimas y restitución de tierras}

Las mujeres campesinas/rurales generalmente no son propietarias y cuando son víctimas del conflicto armado las problemáticas de acceso, formalización y producción de la tierra aumentan. En este contexto, la Ley de víctimas y restitución de tierras, 1448 de $2011^{4}$, se ocupa entre otras cosas de quienes han sido despojados o tuvieron que abandonar ${ }^{5}$ su tierra a causa del conflicto armado. En particular, el art. 114 planteó como "sujeto de especial protección" a las mujeres en los trámites administrativos y judiciales durante el proceso de restitución de tierras. Sin embargo, cuando se observa el cumplimiento de la norma y el avance en las decisiones que se han tomado respecto a la restitución de tierras, se encuentran diferencias significativas entre hombres y mujeres. En especial por la informalidad en la tenencia de la tierra y el desconocimiento de los procedimientos jurídicos en cuanto la restitución de tierras.

La necesaria revisión y atención de las mujeres víctimas del conflicto armado en materia de tierras, ha sido objeto de reflexión de varias instituciones, organizaciones y académicas que han realizado sus aportes en cuanto la incorporación del enfoque de género en la política de restitución de tierras.

De manera más específica, Dejusticia (2014) plantea algunos elementos para comprender el enfoque de género como perspectiva de análisis y como herramienta fundamental en la implementación de la Ley 1448 de 2011. Primero parte de distinguir las diferencias biológicas y las construcciones sociales y culturales que fijan un deber ser para los hombres y las mujeres.

\footnotetext{
4 En la Ley 1448 de 2011 se define la Reparación Integral en el art.25 como un deber del Estado y un derecho de las víctimas (art. 69), la cual parte del reconocimiento del daño causado, la contribución a la reconstrucción del proyecto de vida en sus diversas dimensiones (material, simbólica, moral y colectiva) y garantizar el Goce Efectivo de Derechos -GED-. En concreto, incorpora cinco medidas de acción social: indemnización administrativa, medidas de satisfacción, rehabilitación, restitución y garantías de no repetición.

${ }^{5}$ En la Ley 1448 de 2011, el artículo 74: "entiende por despojo la acción por medio de la cual, aprovechándose de la situación de violencia, se priva arbitrariamente a una persona de su propiedad, posesión u ocupación, ya sea de hecho, mediante negocio jurídico, acto administrativo, sentencia, o mediante la comisión de delitos asociados a la situación de violencia. Se entiende por abandono forzado de tierras la situación temporal o permanente a la que se ve abocada una persona forzada a desplazarse, razón por la cual se ve impedida para ejercer la administración, explotación y contacto directo con los predios que debió desatender en su desplazamiento durante el periodo establecido en el artículo 75".
} 
Señalando que la asignación normativa y hegemónica hace que regularmente, para poner un ejemplo, las mujeres en el sector rural se ocupen de las actividades de reproducción domésticas, encargadas del cuidado; y los hombres más en un rol proveedor, tomen decisiones sobre los recursos requeridos para la supervivencia. A partir de tal definición, resaltan que la incorporación del enfoque de género permite observar de qué manera el conflicto armado afectó los roles tradicionales, provocó tensión en las identidades, así como visibilizar las situaciones de discriminación previas y los efectos desproporcionados del conflicto sobre las mujeres y la población LGBTI.

Dejusticia (2014) describe que una de las limitaciones en el abordaje que se hace desde la Ley 1448 del enfoque de género, parte de insistir en el concepto de hogar y familia como núcleo de reclamación de la restitución, desconociendo las desigualdades en las relaciones entre hombres y mujeres y las condiciones previas o posteriores al abandono de tierras.

En este contexto debe aclararse que se entiende la categoría género desde Joan Scott (1996), que la plantea como categoría útil para romper con un determinismo biológico sobre el sexo y adentrarse a los aspectos relacionales de las definiciones normativas de la feminidad. La pregunta por cómo el género actúa en las relaciones humanas y cómo da significado el género a la organización y percepción del pensamiento histórico, señala que el género es más que un sustituto de mujeres. Refiere el mundo de las mujeres compartido y creado por hombres, por ello da cuenta de las "construcciones culturales". De tal modo, se define el género como: "un elemento constitutivo de las relaciones sociales basadas en las diferencias que distinguen a los sexos y el género es una forma primaria de relaciones significantes de poder" (p.23).

En este orden de ideas, las relaciones sociales en el acceso y tenencia de la tierra se encuentran permeadas por relaciones de género. Retomando a Luz Gabriela Arango (1998) podría decirse que estas relaciones se expresan en tres niveles: la división sexual del trabajo, las relaciones de poder, los valores y las representaciones sobre lo femenino y lo masculino en el campo. De modo empírico, puede observarse dichos niveles en una distribución desigual del trabajo productivo y reproductivo entre los géneros. 
En este sentido, durante el conflicto armado, la propiedad pareciera del orden masculino ya que ante las acciones de despojo y/o abandono de la tierra, en muchos casos fue percibida la posición femenina como una debilidad y una desventaja aprovechada por los actores armados. En particular, cuando algún actor armado se interesaba por una propiedad, amenazaba o desaparecía a los hombres de la familia porque ello suponía facilidades para tomar la propiedad por la fuerza.

A través del Observatorio de Tierras, María Mónica Parada Hernández y Rocío del Pilar Peña Huertas, en el artículo titulado El género: más que una clave para leer la restitución de tierras, plantean que, son múltiples, aunque incipientes, los esfuerzos que el Estado colombiano ha tenido en vincular un enfoque diferencial, siendo el género una categoría muy usada en la formulación de políticas sobre variadas problemáticas sociales: la lucha contra las violencias hacia las mujeres, la salud sexual y reproductiva; el empleo y la educación. Resaltando que si bien se institucionalizaron algunas entidades a nivel nacional y territorial con la creación de oficinas especializadas con unas orientaciones muy genéricas para dar cuenta de las mujeres como sujetos de especial protección, el enfoque diferencial de género en la política de restitución de tierras, tiene su mayor atributo como "herramienta de análisis y actuación social y política" (Parada y Peña, 2019, p. 262).

La categoría de género resaltada como herramienta de análisis tiene su potencia en cuanto devela las relaciones de poder entre hombre y mujeres, así como la necesaria discriminación positiva en programas específicos del Estado. Sin embargo, sigue siendo limitado el planteamiento por la naturaleza mixta del proceso de tierras (proceso administrativo y jurídico) en el marco de la justicia transicional, situando relaciones y momentos que solo en el caso a caso deben atender los jueces especializados de tierras y que plantean retos en la implementación de la categoría de género por las particularidades en las relaciones de poder entre hombres y mujeres según las regiones y localidades.

De manera más específica, Meertens (2016 y 2017) realiza el análisis de género sobre el despojo y los avances en la implementación de la política de restitución de tierras en el Caribe en general y, en particular, para las zonas micro focalizadas en: Cesar, Montes de María, Sucre y Córdoba. En estos informes e investigaciones, Meertens observa en la política de restitución de 
tierras su capacidad transformadora y acciones afirmativas, reconociendo que la tierra encierra dos componentes: uno material y otro moral; la supervivencia y la pertenencia. Situa así dos conceptos: el de restauración de la dignidad — propuesto por Bernadette Atuahene (2014) que analizó procesos de restitución en Sudáfrica- y el de justicia de género, trabajado por la politóloga canadiense Ana María Goetz (2007).

El énfasis analítico le permite comprender a Meertens más allá de la titularidad y formalidad de la tierra, las nociones de justicia de género en un contexto transicional. En el primer concepto, Atuanhene (2014) insiste que se debe ir más allá de la reparación material en tanto que se arrebató la dignidad de los sujetos en los procesos de despojo, indicandose así la necesidad de otros abordajes que van más allá de lo jurídico. Por la segregación o los efectos del conflicto armado en el caso colombiano, esto supone conocer y emprender acciones para recuperar el tejido social y remover las condiciones que afectaron la identidad ante los casos de despojo. Por otro lado, retomar el daño que se ha producido sobre el proyecto de vida, lo cual supone entender el trabajo de redes de apoyo y de promoción de condiciones favorables para la promoción del desarrollo, lo cual no supone necesariamente el retorno a los contextos de despojo.

Meertens retoma del grupo de Memoria Histórica que el despojo tiene varias expresiones o modalidades de acción que pueden realizarse de facto o de manera procesual con igual finalidad, ocupación del predio y apropiación del título, por ejemplo, a través de: "la ocupación armada, compraventa a menor precio, reversa de adjudicaciones por reforma agraria y legalización de la ocupación por vía fraudulenta”. (Centro Nacional de Memoria Histórica, 2013, 33-50)

Meertens (2016) indica, por su parte, que el despojo encarna mucho más que la expropiación de un predio. Al respecto refiere:

aquellos aspectos de la dignidad humana asociados al lugar propio, como el reconocimiento social, la autonomía y la identidad, también han sido profundamente vulnerados. Requieren de su restauración o instauración a través de un amplio proceso de justicia que abarque algo más que resarcir los daños del conflicto armado. En 
palabras de una de las mujeres citadas, justicia es que el Estado les dé apoyo en la reconstrucción de sus proyectos de vida, con respeto a los derechos humanos, con servicios y con un nuevo y más justo orden social y legal. Es la expresión del anhelo de un nuevo contrato social para el posconflicto. Indudablemente, el proceso de restitución de tierras tiene un déficit de justicia en esos términos de restaurar la dignidad, la pertenencia y la legitimidad social. Esto se debe, por un lado, a su inscripción en un modelo de justicia transicional cuyo peso está en reparar el pasado más que en proyectar hacia el futuro, y que evita la confrontación entre el modelo de la justicia implícita en su accionar y el modelo de desarrollo vigente. Por otro lado, el Estado, o la política pública, no pueden actuar directamente sobre las injusticias de género incrustadas en las prácticas sociales, pero sí generar condiciones para que las mujeres actúen sobre ellas a través de sus procesos de empoderamiento. (p. 67)

Los trabajos y análisis realizados por Meertens son sugerentes para avanzar en la discusión sobre la respuesta estatal ante el abandono y despojo de tierras cuando las mujeres son víctimas del conflicto armado en territorios específicos. Sin embargo, el alcance de su planteamiento para este artículo tiene sentido en cuanto devela los aspectos que debe tratarse en cuanto la restitución va más allá de la titularidad de un predio y los sentidos que tiene la tierra más allá de los materiales. 


\section{Un poco de contexto: sobre los casos de abandono en el Sur del Tolima}

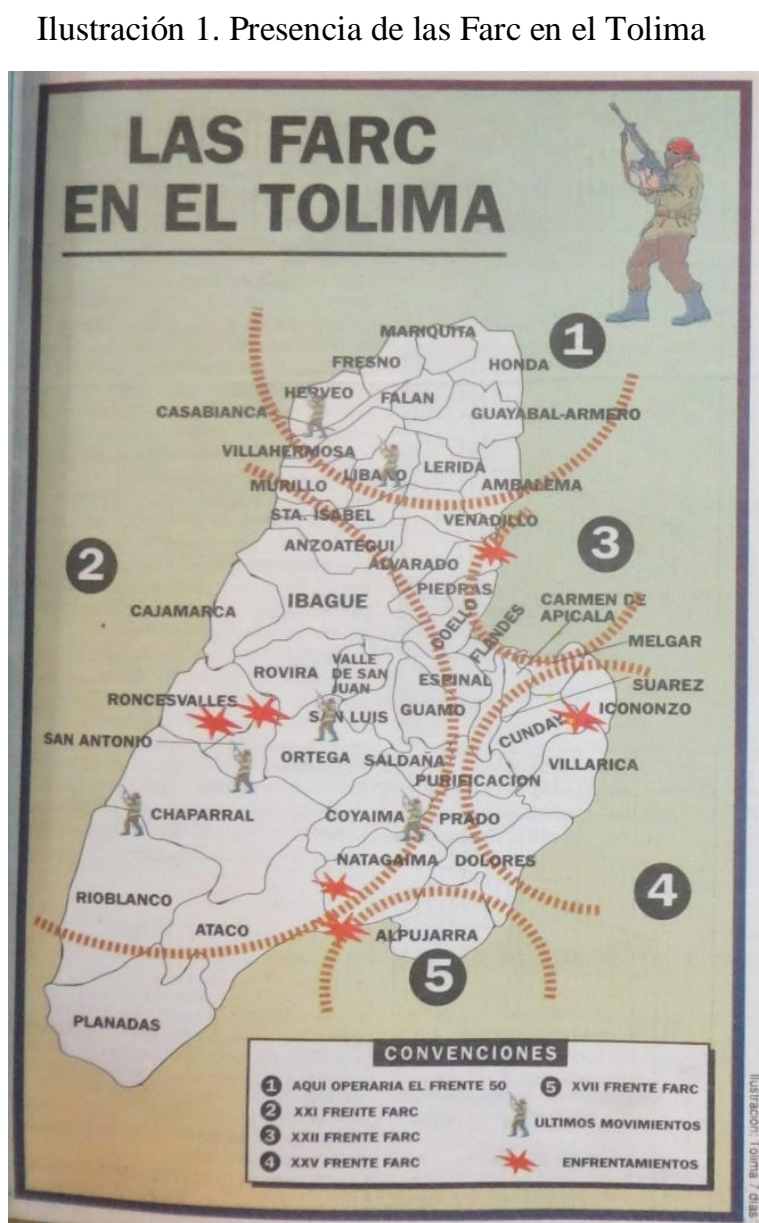

Fuente: Tolima 7 días, Julio 27 a 2 de agosto 1994.

El departamento del Tolima de acuerdo con el informe de la MOE (2007) fue un territorio de valor estratégico para los actores armados, especialmente por su ubicación. Atravesado por la vía denominada La Línea, posibilitó la comunicación con el centro del país, el Eje Cafetero y el Valle de Cauca. También cuenta con vías que comunican con la Costa Atlántica y el sur de Colombia. El departamento se divide en cuatro subregiones. En particular, el sur está conformado por los municipios de Ataco, Alpujarra, Chaparral, Coyaima, Dolores, Natagaima, Ortega, Planadas, Rioblanco y San Antonio. 
La violencia en la región sur tuvo diferentes motivaciones y dinámicas. Especialmente porque fue convertida en corredor de movilidad y sector de permanente disputa entre la guerrilla, la fuerza pública y los paramilitares presentes en el territorio.

Desde la década de 1950 -época marcada por el fenómeno del bandolerismo que suscitó las alianzas entre autodefensas campesinas del sur y liberales, cuya principal reivindicación giraba precisamente sobre el derecho a la tierra-, la dinámica del conflicto presenció una aguda disputa territorial, en la cual la población civil quedo sometida, convirtiéndose en víctima de intimidación, desplazamiento forzado, reclutamiento ilegal, homicidio, desaparición y secuestros.

Al iniciar la década de 1980, el municipio de Ataco fue escenario de acción tanto para los paramilitares como de la guerrilla, en particular el Frente 21 de las Farc, Frente que surgió de la séptima Conferencia (1982) cuyos lineamientos buscaron incrementar la presencia del grupo guerrillero en diversas zonas del país. Así, se asentó en la cordillera Central como grupo de defensa del sur del Tolima y como contingente que se movilizó en el corredor estratégico que sobre esta cordillera se delineaba, lo que facilitó desplegarse desde el sur de Tolima hasta Ibagué, el Eje Cafetero y Cundinamarca (Medina, 2011). De hecho, "las alturas superiores a los 5000 metros sobre el nivel del mar les ha permitido a los frentes guerrilleros establecer zonas de repliegue y corredores vitales en los desplazamientos hacia los departamentos del Valle, Quindío, Risaralda y Caldas" (El Tiempo, 2002).

De acuerdo con informes del Sistema de Alertas Tempranas de la Defensoría del Pueblo, los actores armados mantuvieron el control sobre la población mediante censos ilegales sobre las personas y cultivos con el fin de imponer sanciones, lo que provocó el desplazamiento de quienes no aceptaron estas exigencias. Los desplazamientos tuvieron lugar luego de amenazas y la aparición de listas que señalaron a las personas como auxiliares de uno u otro bando.

En general, en el sur del Tolima se presentaron abandonos por el temor de la población a la violencia generalizada en el marco del conflicto armado. Respecto a ello, debe resaltarse el potencial organizativo de las mujeres desplazadas, sobre lo cual un personero de uno de los municipios del sur señaló: 
ha tenido un auge en las organizaciones de mujeres y me parece muy bueno. Las asociaciones de mujeres son muy verracas, porque son de mujeres, de mujeres campesinas, son de mujeres trabajadoras, productoras y personas que viven en el territorio y que han vivido en carne propia la violencia (Sic). (Carlos, comunicación personal, 25 de abril 2017)

Sin embargo, las mujeres campesinas/rurales en materia de propiedad no eran muy reconocidas. Aquí podría destacar algunos aspectos de la experiencia compartida ${ }^{6}$ con participantes de las actividades de recolección de información comunitaria para la elaboración de documentos de análisis de contexto $-\mathrm{DAC}^{7}$-. Al respecto, el mayor reconocimiento que se hacía de la participación de la mujer en las actividades productivas se centraba en la preparación de alimentos para los trabajadores, por tanto, el tema de "trabajo de la tierra era un tema de los hombres". (José, comunicación personal, 13 de diciembre 2017)

Así, en cuanto a la propiedad y el trabajo agrícola era un atributo ampliamente reconocido como de dominio masculino por tradición, tanto que en otra entrevista también se resaltó:

En el caso de mi papá, por lo menos él era él, -si me entiende-, él murió y todos los papeles de la finca están a nombre de él, mi mamá no figura por ningún lado y vivió 45 años con él. (José, comunicación personal, 13 de diciembre 2017)

Otra de las características relatadas por los campesinos es la alta informalidad en cuanto al acceso a la tierra, así lo describían:

pero llegué a esta tierra y a los cuatro meses era dueño de una finca, porque por aquí la facilidad le fiaban a uno entonces le decía a uno, coja tierra y hágale y me la va pagando (...). Entonces más o menos en el 2003 la gente podía llegar y decirle mire, le vendo este pedazo de tierra y páguemela cuando pueda. Por ejemplo, decir: Sí me da tanto y le sigo pagando con la misma finca, con la misma cosecha se pedía pagar. (Daniel, comunicación personal, 2 de febrero 2018)

\footnotetext{
${ }^{6}$ Realicé tareas como analista de contexto en la Territorial Tolima, Unidad de Restitución de Tierras, durante los años 2016, 2017 y algunos meses del año 2018.

${ }^{7}$ Los documentos de análisis de contexto constituyen pruebas sociales en el marco del proceso de restitución de tierras. Se producen como informes de investigación social y dan cuenta de las condiciones de modo, tiempo y lugar que permiten explicar el presunto rompimiento del vínculo con la propiedad del solicitante por experiencias de abandono y despojo a causa del conflicto armado.
} 
Las características presentadas, si bien resultan muy generales en cuanto a las dinámicas de violencia, abandonos y formas de acceso y tenencia de la tierra, permiten demostrar la complejidad que viven las mujeres para demostrar su vínculo con la propiedad ${ }^{8}$ en un proceso de restitución de tierras.

\section{Sobre el proceso de Restitución de Tierras}

No sabíamos nada de restitución de tierras, yo como en un año vine a entender bien como era. Al principio eran pocos los que llevaron los papeles, había mucha desconfianza, porque por allá no había ido ninguna institución. La desconfianza también porque el día que mataron a una persona allá en Montefrío donde se une Natagaima y Ataco, habían citado a una reunión. No llegó nadie y los que llegaron fueron los que mataron. Cuál más no iba a salir a una reunión así.

Esa reunión de restitución fue como fines de 2011, a esa reunión fuimos con mi mamá y mis hermanas. Cuando llegamos ya estaban terminando y era pa' entregar los documentos. Ellos escanearon los documentos, hicieron una jornada allá y quedamos a la espera con la expectativa.

Ellos empezaron a llegar más seguido y nos iban explicando, pero en ese momento no nos decía que esto llegaba con casa y con proyecto, o sea ellos nos hablaban tan institucionalmente, unas palabras que no se entendía, no profundizaban que eso venía con lo del proyecto, llevaban un reguero de cosas que uno le daba hasta pereza y uno al principio no se le puso mucha atención. Hasta que un sr de por ahí sí le explicaron, fue un abogado que le dijo con qué venía, después ya los abogados nos explicaron.

Ellos llegaban arriba y preguntaban de pronto por otro vecino, que si vivía en Balsillas, que si distinguían a tal persona, y que si podía responder unas preguntas, y pues claro si uno conocía sí, en ese momento ya estábamos capacitándonos con Colombia

\footnotetext{
${ }^{8}$ Uno de los criterios para realizar la inscripción al Sistema de Registro de Tierras Despojadas y Abandonadas cuando se presenta una solicitud es que se demuestre que se cumplían funciones de amo, señor y dueño en el bien solicitado. Situación que para algunas mujeres es complicado demostrar cuando no logran determinar claramente los límites de las propiedades, no puede demostrar con facturas o servicios algún tipo de crédito solicitado sobre mejoras o ventas de cosecha. Actividades que podrían haber dejado algún soporte pero que ellas desconocen ya que son labores que regularmente realizaban o era atribuidas a los hombres del hogar.
} 
Internacional. Ahí fue cuando leíamos lo que otros habían hablado de nosotros, que nos habían investigado, que había dicho que estudiábamos juntos y que habíamos vivido toda la vida por ahí, que distinguían a mis papás y todo. Una vez cuando me preguntaron por el señor Jairo, que cómo se llamaba la finca, y pues ahí si no, uno sabía que vivía ahí pero no el nombre, qué hace cuánto lo había visto, así del momento del desplazamiento. Yo no recuerdo mucho de las entrevistas, pero sí que nos citaban, pero llegaban sin seguridad porque eso ya estaba calmado por allá.

No es que no nos explicaran, era que no atendimos a los derechos que teníamos como víctimas, por ejemplo, en la hechura de las casas y proyecto. En ese momento no teníamos el conocimiento pa' entender, ya después nos dimos cuenta que podíamos haber pedido que las casas que nos dejaron estuvieran en mejores condiciones. Ese fue el único problema que tuvimos.

Eso salió como en el 2013, duró como dos años, eso la entregaron en la vereda Canos San Roque que quedaba más central. Hay una caseta comunal que había, las entrego el director, pero no recuerdo bien, fue una comisión grande. (Ana ${ }^{9}$, comunicación personal, 22 de febrero de 2020)

La política de restitución de tierras define sobre qué sujeto actuar mediante determinados instrumentos y escenarios. Describir estos elementos permite la delimitación del campo burocrático del que hacen parte las mujeres solicitantes. Implica reconocer el tipo de capitales requeridos para ser parte de un proceso administrativo y jurídico desde los diferentes agentes sociales, de los solicitantes hasta los funcionarios vinculados con la regulación de la propiedad de la tierra en el campo rural.

El campo burocrático, "como todos los campos, es el resultado instituido en un momento dado de las luchas y enfrentamientos pasados y presentes de intereses

\footnotetext{
9 Ana Jesús Valderrama, mujer de 46 años, casada hace 28 años. Con cinco hijos, cuatro hombres y una mujer. Sus hijos tienes 27, 25, 22, 21 y 19 años. Tres viven con ella. Estudió hasta séptimo. Vive en la vereda Canoas Copete, en el municipio de Ataco. Es propietaria, logró formalizar su propiedad a través de la Restitución de Tierras. Trabajaban con café. Antes tenía un documento de compra venta, "eso fue como en el año 1995. En ese entonces se hacía un esfuerzo muy grande, con créditos, llevábamos cinco años y pagábamos cuotas anuales".
} 
contradictorios de agentes que están en el campo o fuera del campo, pero que se encuentran en el campo de las posiciones, apoyos y medios, en particular jurídicos, para defenderlos según la lógica propio del campo (...). El campo de las instituciones estatales -y ahí está el fundamento del efecto de neutralidad real e ideológica que produce- tiende a dejar un espacio cada vez mayor a instituciones que son el producto de la transacción entre las clases y que están en parte, o en todo caso lo parecen, situadas más allá de los intereses de clase. (Bourdieu, 2014, p.518)

Analizar a través de los casos de restitución de tierras cómo las mujeres interactúan en un campo burocrático supone conocer: los modos de formalización y/o titulación de la propiedad en contextos de justicia transicional, el modo en que se ocupa el territorio y la interacción que supone las nuevas instituciones creadas para el desarrollo rural. Escenario a partir del cual se pueden construir reflexiones sobre las relaciones de género en el sector rural en un contexto de posacuerdo.

A través de la Unidad de Restitución de Tierras, institución del Estado colombiano y que depende del Ministerio de Agricultura, se puso en funcionamiento la política de tierras para quienes fueron víctimas del conflicto armado. A partir del 2012, se crearon diferentes sedes territoriales, y actualmente cuenta con 26, poniendo en funcionamiento un modo de atención administrativo y jurídico para la formalización de la tenencia de la tierra en contextos donde el conflicto armado generó acciones de despojo y abandono a partir de 1991.

En general, el proceso de restitución de tierras cuenta con varias etapas e implica la relación con diferentes actores sociales e institucionales. El proceso administrativo se inicia con la solicitud que interpone el solicitante ante la institución. Recibida la solicitud, cuando la zona ha sido micro-focalizada ${ }^{10}$, inicia la fase de estudio que, a través de una resolución de inicio, da lugar a la etapa de apertura a pruebas. Posteriormente, se decide si se inscribe o no la solicitud al

${ }^{10}$ Los términos macro focalización y micro focalización corresponden a la manera cómo se fue determinando el modo progresivo y focalizado para llevar a cabo el proceso de restitución de tierras. Las zonas macro focalizadas eran áreas geográficas de gran extensión definidas por el Ministro de Defensa, Ministro de Agricultura, el director de la Agencia de Desarrollo Rural y el director Nacional de la Unidad de Restitución de Tierras. Este fue el primer proceso para la creación de las Unidades Territoriales y, posteriormente, se definieron las zonas de micro focalización, áreas de menor extensión que hacían parte de las zonas de macro focalización y que eran definidas porque cumplían las siguientes características: condiciones de seguridad, densidad histórica del despojo y condiciones para el retorno. 
Sistema de Registro de Tierras Abandonas y Despojadas (SRTAD) por el cumplimiento de unos criterios $^{11}$.

Todo el proceso no refiere ningún costo para el solicitante y a través de un abogado sustanciador, el Estado se hace responsable de la construcción del expediente conformado con pruebas sociales, catastrales y jurídicas que aporta las áreas misionales de la Unidad de Restitución de Tierras: la jurídica, la catastral y la social.

En caso positivo de inscribirse una solicitud al sistema de registro de tierras, se pasa a la construcción de la demanda que da apertura al proceso jurídico ${ }^{12}$. Los tribunales especializados en tierras son quienes toman las decisiones de restituir o no de los predios y mediante sentencias judiciales decretan una serie de medidas para garantizar la propiedad y el disfrute del bien.

El municipio de Ataco ha sido microfocalizado de manera progresiva. Primero, mediante la Resolución de inicio (RI) 02078 del 2 de mayo 2012; posteriormente, por la RI 02077003 del 14 de agosto de 2012; RI 0446 del 28 de septiembre de 2017 y, finalmente, RI el 13 de diciembre de 2017. De modo general, cuenta con 942 solicitudes de restitución en trámite y se han proferido 317 sentencias. De ellas, 175 resultaron a favor de las mujeres como titulares del derecho y los 269 restante son a favor de hombres ${ }^{13}$.

Es importante aclarar que Ataco fue una de las primeras zonas microfocalizadas por la territorial Tolima. La gestión de la unidad de tierras inició en cuatro veredas específicas: Balsillas, San Roque y Canoas la Vaga y Canoas Copete. Zonas sobre las que se decidieron las primeras sentencias y las que sirven de referencia para describir cómo ha sido el proceso vivido por las mujeres restituidas.

Ahora, para cumplir el propósito de este artículo, se retomarán dos informes de trabajo que se han realizado sobre dicha población: una caracterización de la Corporación Humanas (2017) y

\footnotetext{
${ }^{11}$ Quienes tienen derecho a la restitución, según el artículo 75 de la Ley 1448 de 2011, son aquellos que logren demostrar en el proceso administrativo su calidad de: propietarios, poseedores y ocupantes. Además, demostrar el rompimiento del vínculo con propiedad o bien a causa del conflicto armado y calidad de víctima" en una temporalidad que parte del 1 de enero de 1991.

12 La unidad de restitución de tierras cuenta desde el área jurídica, con dos equipos de abogados: los de la fase administrativa y los de la etapa judicial. También con un equipo de pos fallo que son los encargados de acompañar el cumplimento de algunas medidas de la sentencia judicial.

${ }^{13}$ Corte a septiembre de 2019. Respuesta a derecho de petición mediante el DTTI2-201903239 de la Unidad de Restitución de Tierras.
} 
otro sobre una evaluación del Estado de cumplimiento de las órdenes y sentencias en dicho territorio realizado por una consultora de la USAID $(2017)^{14}$.

La caracterización de la Corporación Humanas analizó 28 sentencias que hacen parte de la primera resolución de micro focalización y sobre ellas logra hacer una presentación general que indica:

- La mayoría de reclamantes son mujeres adultas y adultas mayores, campesinas de origen, con educación básica (primaria), la mayoría incompleta, con altos índices de analfabetismo jurídico y con personas a su cargo o ellas mismas a cargo de otra persona (...).

- Las mujeres de Ataco manifestaron tener jornadas de trabajo de más de 12 horas, entre las 5 am y cerca de las 9pm. Las principales actividades que realizan se relacionan con las labores de cuidado de hijos, hijas, compañero y del hogar. Esto significa preparación de alimentos, organización de la vivienda, arreglo de uniformes, cuidado de animales, entre otras actividades relacionadas con la limpieza y el orden. (Corporación Humanas, 2017, p. 13)

Debe señalarse a partir de las características de las mujeres que una de las primeras dificultades presentadas en el proceso administrativo y jurídico correspondió precisamente a la comprensión del proceso y la descripción del vínculo con la propiedad, ya que muchas no eran propietarias.

Demostrar la posesión de la tierra es un primer reto para algunas mujeres que no tienen claridad sobre los límites y extensión de la propiedad, así como el modo de explotación. Para varias mujeres, esta era una tarea de sus compañeros permanentes que en muchos casos las abandonaron, fueron asesinados, desaparecidos o tienen nuevas familias y no se interesan por retornar a los predios que antes ocupaban. Las mujeres así deben acudir a quienes eran sus vecinos para que mediante testimonios que exige la Unidad de Restitución de Tierras, puedan demostrar que habitaban el predio y era explotado por ellas. Así uno de los requisitos fundamentales para avanzar en el proceso administrativo y judicial, como lo es la

14 Documento interno de USAID que no fue publicado y compartido por la profesional que lo realizó cuando cumplía tareas como analista de contexto de la Territorial Tolima, Unidad de Restitución de Tierras. 
individualización de los predios, se convierte en una barrera para algunas mujeres dadas la división sexual del trabajo en el campo.

Ahora ya en las sentencias de los jueces, se puede observar que la mayoría eran poseedoras y la extensión de sus predios no alcanzaba ni siquiera a cumplir con una UAF (unidad agrícola familiar).

Al ser este uno de los primeros procesos realizados por la territorial, los abogados (as) responsables de los casos por parte de la territorial realizaron desplazamientos hasta los predios para aclarar los procedimientos y en pocos casos se realizaron audiencias para ampliar las pruebas de los casos.

En unas sentencias los juzgados certificaron que la extensión de las UAF es de un rango entre 11 y 17 hectáreas, por lo cual se asume dicho rango para efectos del análisis de la extensión de los predios en el presente documento. Del total de 36 predios analizados se tiene que más de la mitad no logran conformar una unidad agrícola familiar porque la extensión de los predios es inferior a 11 hectáreas $(52,8 \%)$. Solamente un predio está en el rango descrito para la UAF $(2,8 \%)$ y los restantes superan la extensión de una UAF (30,6\%). Sobre 6 casos no se cuenta con información (16,7\%). La mayoría de los predios sobre los que se presentó reclamación tiene vocación agrícola $(58,3 \%)$, seguido de aquellos con destinación agropecuaria $(27,7 \%)$. Ninguno tiene vocación pecuaria y en cinco casos no se cuenta con información (13,8\%). (Corporación Humanas, 2017, p. 17)

Determinar la vocación del predio es una prioridad para poder ordenar lo referido a los proyectos productivos. Sin embargo, al prestar atención a la edad de las mujeres restituidas, se observó que la mayoría estuvo sobre los 50 años, aspecto que en algunos casos refirió dificultades para el trabajo sobre la tierra. Situación que supone contar con otros miembros de la familia que puedan apoyar con las actividades agrícolas o de gestión y que en ocasiones no son fáciles de sobrellevar por las relaciones de poder al interior de los hogares. Se convierte así este en otro aspecto procedimental que genera una barrera para las mujeres restituidas.

Mediante las sentencias que los jueces especializados en tierras profieren no solo se emiten órdenes para formalizar la propiedad de la tierra, también otras que garanticen la 
explotación del bien y se restablezca o garantice el goce efectivo de derechos. Entre las otras medidas se encuentran: proyectos productivos, subsidios de vivienda, alivio de pasivos, acceso a salud y educación, etc.

Así, el proceso de restitución de tierras para ser efectivo requiere de una respuesta coordinada y complementaria por parte de diferentes entidades del orden nacional y municipal que conforman el Sistema Nacional Atención y Reparación Integral a las Victimas -SNARIVPor ejemplo: el Juzgado Promiscuo Municipal, el Banco Agrario, la Agencia Nacional de Tierras, la Secretaría de Desarrollo Social, la Secretaría de Hacienda, Comfatolima, la Secretaría de Desarrollo Agrícola y Producción Alimentaria, el IGAC, la Policía, Cortolima, la Dirección de DDHH de la Gobernación, el ICBF, la Oficina de Registro de Instrumentos Públicos, el SENA y la Defensoría, entre otros. Entidades que en la mayoría de los casos no cumplen con las órdenes a tiempo y sobre las que no hay formalizado un seguimiento para el cumplimiento de las órdenes y que las mujeres no alcanzan a comprender como hacer dicho seguimiento.

De acuerdo con el informe realizado por la USAID, sobre el Estado de cumplimiento de las órdenes y sentencias en dicho territorio, las mujeres restituidas en la primera micro focalización de Ataco tienen alto cumplimiento en cuanto el alivio de pasivos y el proyecto productivo. Contrario a este planteamiento, algunas mujeres entrevistadas, quienes son mujeres mayores de 60 años, expresan dificultades con los desembolsos y en el acompañamiento para la definición de proyectos productivos que sean acordes con la vocación de los predios y el momento vital de las restituidas, Además, presentan bastantes problemas con los subsidios de vivienda y frente a las otras medidas no hacen seguimiento.

Sin embargo, una de las cosas que más llama la atenciónn según el informe de cumplimiento de las ordenes tiene que ver con el cumplimiento de un enfoque de género, en especial cuando se trata de entidades como la Secretaría de Desarrollo Social, Comfatolima, el ICBF o el SENA, que tienen a su cargo medidas de reparación con un fuerte componente social asociado a la salud, educación, transporte, Familias en acción y vivienda.

Todas estas situaciones hacen que las mujeres entrevistadas expresen que si bien observan una respuesta estatal, tienen temores en cuanto varias situaciones, por ejemplo: acciones de violencia que les lleven a tener que desplazarse nuevamente; la precariedad de las viviendas recibidas; la falta de acceso a servicios públicos; la distancia entre ellas y sus hijos e hijas frente a 
su vínculo con la tierra; sostenibilidad de los proyectos productivos; el incumplimiento en la construcción de las vías que les permitan comunicarse con los demás municipios y les de salida a sus productos.

Lo descrito presenta un reto institucional muy alto para garantizar el retorno a los predios abandonados, demuestra que no basta con las sentencias o las ordenes proferidas por el juez de tierras. La implementación de la Ley 1448 indica que más allá del acompañamiento institucional en la fase administrativa y judicial, se deben atender las condiciones que promuevan una justicia de género retomando lo descrito más arriba por Meertens. Aspecto que solo hasta después de tres o cinco años de emitidas las sentencias se empiezan a visualizar.

Ahora, si bien todo el proceso de restitución se enmarca en un proceso de Justicia Transicional, es notorio que la flexibilidad de ciertas formalidades no omite el lenguaje jurídico de las sentencias, lenguaje y formas que las mujeres rurales no alcanzan a comprender. Desconocen los documentos que les son entregados y cómo puede hacer uso de ellos. Por ello se hace necesario de promover el desarrollo de un proceso pedagógico para que comprendan los apartes de las sentencias, las medidas que se ordenan y el modo en que pueden hacer de ellas instrumentos de exigibilidad para el cumplimiento de las medidas de reparación integral.

Aspecto que lleva a insistir en la necesidad de promover el diseño e implementación de programas de prevención, asistencia, atención, protección y reparación integral a las víctimas; con asignaciones presupuestales dentro de los respectivos planes de desarrollo y acordes con los lineamientos establecidos en el Plan nacional de atención y reparación de víctimas. (Ley 1448, 2011, Art. 174)

Finalmente, debe resaltarse que la tenencia y formalización de la tierra resulta una realidad problemática para las mujeres campesinas/rurales a nivel nacional y de la cual no es ajena al municipio de Ataco. Así que debe considerarse y prestarse atención sobre las medidas de restitución para que realmente permitan mejorar las condiciones de vida de las mujeres con predios cuya extensión corresponda como mínimo a una unidad agrícola familiar, con toda una serie de capacitaciones y dotación de recursos que aseguren que efectivamente su situación será mejor que antes del abandono o despojo de sus tierras. 
Las características presentadas, si bien resultan muy generales en cuanto a las dinámicas de violencia, abandonos y formas de acceso y tenencia de la tierra, busca demostrar la complejidad que viven las mujeres para demostrar un vínculo con la propiedad en un proceso de restitución de tierras. Situación que se ha enfrentado con diferentes recursos comunitarios e institucionales que se han adelantado a partir del 2012 para fortalecer la implementación de la política. Si bien hasta el momento se han realizado diversos estudios desde una perspectiva jurídica para identificar avances y limitaciones en la implementación de la política de tierras, son pocos los que han indagado desde la posición de los sujetos del derecho cómo se han generado capacidades en los territorios en un contexto de posacuerdo, tarea que actualmente me ocupo en el desarrollo de la tesis doctoral en Sociología de la Universidad del Valle y del cual se derivó el presente artículo.

\section{Conclusiones}

Para la población campesina, la Unidad de Restitución de Tierras se presenta como una institución estatal que difícilmente comprende su labor. Solo hasta trascurrido la intervención es que se logra tener una idea general del proceso. Sin embargo, es común relacionarla con la labor del antiguo Incoder ahora denominado Agencia Nacional de Tierras. De tal modo, La Unidad de Restitución de Tierras se enfrenta con la desconfianza que se presenta en los territorios por la escasa efectividad de la acción estatal en el ámbito rural y por el miedo que dejó el conflicto armado. Las reuniones o las invitaciones a procesos de organización se perciben con recelo, ya que mediante estas acciones se realizaron hechos victimizantes que propiciaron el abandono o despojo de los predios solicitados en restitución.

La mayoría de las veces, los solicitantes de restitución de tierras esperan poder formalizar la titularidad de los predios que abandonaron y desconocen las otras medidas que acompañan la restitución. Solo mediante la ejecución de las sentencias y el seguimiento logran comprender la integralidad de las acciones. Si bien las primeras experiencias de micro focalización se dieron de un modo más ágil en cuanto la resolución de las sentencias por parte de los jueces, las solicitantes refieren tardanza e incumplimiento de las órdenes de los jueces por parte de las instituciones del sistema general de atención. Las mayores dificultades se presentaron en materia de soluciones de vivienda, las construcciones, los tiempos y los materiales. Situación que amerita un 
acompañamiento institucional para que las mujeres restituidas sepan a dónde acudir y qué procedimientos realizar para que las ordenes tengan un cumplimiento adecuado.

El nivel de escolaridad que presentan las mujeres restituidas en esta primera fase de la micro focalización de Ataco demuestra la necesidad de desarrollar procesos pedagógicos para la comprensión del lenguaje jurídico en el que se emiten las sentencias, ya que las mujeres prestan poca atención a lo ordenado y no comprenden lo escrito a pesar de poder leerlo. Así las cosas, los os procesos de restitución de tierras son una oportunidad para develar las condiciones desiguales de poder que viven las mujeres rurales/campesinas y con ello abren una ventana de posibilidad de transformación en la medida que desde un enfoque de género puedan emprenderse situaciones y relaciones donde las mujeres se reconozcan como sujetos de derecho.

\section{Referencias bibliográficas}

Arango, Luz Gabriela. (1998). Del paternalismo al terror de mercado. Género, reestructuración y relaciones laborales en la industrial textil. En: Centro de Estudios Sociales- CES. Mujeres, hombres y cambio social. Bogotá: Universidad Nacional.

Bernadette, Atuahene. (2014). We Want What's Ours. Oxford: University Press.

Bourdieu, Pierre. (2014). Sobre el Estado. Cursos en el Collège de France. Barcelona: Editorial Anagrama.

Centro Nacional de Memoria Histórica. (2013) ¡Basta Ya! Colombia: Memoria de Guerra y Dignidad. Bogotá: Centro Nacional de Memoria Histórica.

Cepal, Observatorio de igualdad de género de América Latina y el Caribe (OIG). (2011). Informe Anual. Chile: ONU Mujeres, UNFPA, Organización Panamericana de la Salud, AECID, Secretaría General Iberoamericana, Secretaría de Estado de Cooperaciones Internacionales. Recuperado en: https://www.comisionporlamemoria.org/archivos/investigacion/capacitaciones/genero/u1/ 1-cepal-2011-de-los-margenes-al-centro.pdf

Corporación Humanas. (2017) Caracterización de las condiciones para el cumplimiento de lo ordenado en las sentencias de restitución de tierras. Municipios de Ataco (Tolima), 
Ciénaga (Magdalena) y Valencia (Córdoba). Bogotá. Recuperado en: https://humanas.org.co/alfa/dat_particular/ar/Caracterizacion.pdf

Corte Constitucional [Corte Constitucional de la República de Colombia]. Auto 092 de 2008. Protección de los derechos fundamentales de las mujeres víctimas del desplazamiento forzado por causa del conflicto armado, en el marco de la superación del Estado de cosas inconstitucional declarado en la sentencia T-025 de 2004. Magistrado Ponente: Manuel José Cepeda Espinosa.

Corte Constitucional [Corte Constitucional de la República de Colombia]. Sentencia C-715 de 2012, M.P Luis Ernesto Vargas Silva. Referencia: expediente D-8963 (2012).

Congreso de la República (2011). Ley 1448 de 2011. Recuperado en: http://www.secretariasenado.gov.co/senado/basedoc/ley_1448_2011.html

Deere, Carmen Diana y León, Magdalena (Ed.). (1986). La mujer y la política agraria en América Latina. Bogotá, Colombia: Siglo veintinuno editores.

Dejusticia. (2014). Restitución de tierras y el enfoque de género. Bogotá. Recuperado en: https://www.dejusticia.org/wp-con

El Tiempo. (2002, 30 de abril). La guerrilla cambia su accionar. El Tiempo. Recuperado en: http://www.eltiempo.com/archivo/documento/MAM-1342735

Food and Agriculture Organization. FAO. (2009). El empleo de las mujeres rurales, lo que dicen las cifras. Recuperado en: http://www.fao.org/3/a-i0616s.pdf

Giarracca, Norma (Comp). (2001). ¿Una Nueva ruralidad en América Latina? Buenos Aires: CLACSO.

Goetz, Ana María. (2007) Justicia de género, ciudadanía y derechos. Conceptos fundamentales, debates centrales y nuevas direcciones para la investigación. En: Mukhopadhyay, Maitrayee y Singh, Navsharan. Justicia de género, ciudadanía y desarrollo. Canadá. Centro Internacional de Investigaciones para el Desarrollo (IDRC) 
Meertens, Donny. (2006). Tierra, derechos y género. Leyes, políticas y prácticas en contextos de guerra y paz. Informe Final de la Consultoría sobre Derechos de las Mujeres a la Tierra. Bogotá: UNIFEM Programa Paz y Seguridad.

Meertens, Donny . (2016). Entre el despojo y la restitución: reflexiones sobre género, justicia y retorno en la Costa Caribe colombiana. Revista Colombiana de Antropología, 52(2),. pp. 45-71.

Meertens, Donny . (2017). Restitución de tierras, justicia de género y paz. Instituto de Derechos Humanos, Alfredo Vásquez Carrizosa. Bogotá: Pontificia Universidad Javeriana.

Misión de Observación Electoral - MOE (2007). Monografía Político Electoral Departamento de Tolima 1997 a $2007 . \quad$ Recuperado en: http://moe.org.co/home/doc/moe_mre/CD/PDF/tolima.pdf

Medina, Carlos. (2011). FARC-EP Flujos y reflujos. La guerra en las regiones. Bogotá: Universidad Nacional de Colombia.

Parada, Mónica y Peña, Rocío. (2019). El género: más que una clase para leer la restitución de tierras. En: Gutiérrez, Francisco. La tierra prometida. Balance de la política de restitución de tierras en Colombia. Bogotá. Editorial Universidad del Rosario. Oxfam, (2016). Desterrados, tierra, poder y desigualdad en América latina. Recuperado en: http://209.177.156.169/libreria_cm/archivos/pdf_1485.pdf

Programa de las Naciones Unidas para el Desarrollo - PNUD. (2011). Colombia Rural, razones para la esperanzar en: http://www.co.undp.org/content/colombia/es/home/library/human_development/informenacional-de-desarrollo-humano-2011.html

República de Colombia. (1961). Ley 135 de 1961.

República de Colombia. (1993). Ley de Mujer Cabeza de Hogar (No. 82 de 1993).

República de Colombia. (1988). Ley 30 de 1988. Diario Oficial no 38.264 de 22 de marzo de 1988, Bogotá, D.E., República de Colombia, 18 de marzo de 1988. 
República de Colombia. (1994). Ley 160 de 1994. Diario Oficial no 41.479 de 5 de agosto de 1994, Santafé de Bogotá, D. C., República de Colombia, 3 de agosto de 1994.

Scott, Joan. (1996) El género: Una categoría útil para el análisis histórico. En: Lamas Marta (Comp.). El género: la construcción cultural de la diferencia sexual. México: PUEG. 265-302p.

Tolima 7 días (1994, 27 de julio al 2 de agosto). Presencia de las Farc en el Tolima.

Villarreal, Norma. (2004). Sectores campesinos, mujeres rurales y Estado en Colombia por Norma Villarreal (Tesis doctoral). Universidad de Barcelona. Recuperado en: https://www.tdx.cat/bitstream/handle/10803/5122/nvm1de2.pdf?sequence=1

\section{Fuentes primarias}

Entrevistas realizadas a personero del sur del Tolima.

Entrevista realizada actores del territorio.

Entrevistas a mujeres y solicitantes de restitución de tierras. 